\title{
Study of Chemo-Rheological Behavior of Newly Developed $N$-Benzylquinoxalinium Hexafluoroantimonate/Diglycidylether of Bisphenol A System
}

\author{
In-Ho MYUnG, Jae-Rock LEE, ${ }^{*}$ and In Jae CHUNG ${ }^{\dagger}$ \\ Department of Chemical Engineering, Korea Advanced Institute of Science and Technology, \\ Yusong, Taejon 305-701, Korea \\ *Advanced Materials Div., Korea Research Institute of Chemical Technology, \\ P. O. Box 107, Yusong, Taejon 305-600, Korea
}

(Received June 8, 1999)

\begin{abstract}
Cure reactions of epoxy resin with a newly developed cationic catalyst ( $N$-benzylquinoxalinium hexafluoroantimonate, $N$-BQH) were investigated by using Fourier transform infrared spectroscopy (FT-IR) and differential scanning calorimetry (DSC). The change of rheological property during the cure reaction was studied by dynamic shear measurements. The cure reaction involves three consecutive reactions and the overall kinetic parameters for these reactions were obtained by using the isothermal DSC technique. This catalytic epoxy resin system seems to contain the very complex kinetic reaction mechanisms. The cross-linking activation energies $\left(E_{\mathrm{c}}\right)$ for the various catalyst concentrations are in the range of 56 to $57 \mathrm{~kJ} \mathrm{~mol}^{-1}$; these results show that the overall curing mechanisms are nearly the same. The damping factor curves after gel point showed fluctuating behavior with curing time, especially in the case of $5.0 \mathrm{~mol}$ $\%$ sample.
\end{abstract}

KEY WORDS Cationic Cure / Thermally Latent Initiator / Thermal and Rheological Property /

Among several thermosetting polymers, epoxy resins are used in the largest quantity for addition-cured formulation and generally utilized in advanced composites as matrices due to their excellent mechanical and thermal properties. They also have good electric insulating properties, adhesiveness and weather resistance. So they have been used as a supporting material for printed circuit boards, paints, electric insulating materials, stabilizer for vinyl chloride, and various coating materials. It is easy to handle and process them without the evolution of by-products. The curing agents can be classified as either direct participants in the cross-linked network or promoters in catalytic cross-linking reaction. They participate directly in the reaction and are incorporated in the cross-linked network. They can be subdivided into basic or acidic curing agents. The basic curing agents include Lewis bases, inorganic bases, primary and secondary amines while the acidic curing agents can be carboxylic acid anhydrides, phenol and Lewis acids. The latter reacts by opening the epoxy ring either anionically or cationically. The catalytically functioning curing agents do not directly participate in the cross-linked network but promote reactions between epoxy groups themselves. A newly developed cationic catalytic curing agent, $N$-benzylquinoxalinum hexafluoroantimonate $(N-\mathrm{BQH})$, has a storage time more than 3 months at room temperature, initiate the curing reaction in a short time, and has low hygroscopic property, and excellent water and solvent resistance.

Cationic epoxy curing ${ }^{1-4}$ with a focus on long term storage stability and latent curing properties for electrical applications is another aspect being studied increasingly. Pappers et al. ${ }^{3}$ and Endo et al. ${ }^{4}$ proved that several sulfonium salts act as thermally latent cationic initiator in the curing reaction of epoxy resins, cyclic ethers, and vinyl monomers. Gu et al. ${ }^{5}$ and Morio et al. ${ }^{6}$ observed

${ }^{\dagger}$ To whom correspondence should be addressed. that the aliphatic sulfonium salts can also be excellent thermally latent initiators for epoxy resins without any co-initiator. The network formation leading to crosslinking in polymers is a complex process which is of specific interest in both basic and applied studies. A curing process is involved in the reaction which the monomeric or oligomeric polyfunctional epoxide is transformed into a cross-linked macromolecular structure. Understanding of the curing reaction is important in order to obtain consistent products with the desired physical and mechanical properties. As the reaction proceeds, the thermosetting polymer undergoes immense changes in rheological properties resulting in a rapid increase in molecular weight. At the gel point, there is an irreversible process from a viscous liquid to an elastic, insoluble network. Gelation does not inhibit the reaction. Nevertheless, from a processing point of view, it is critical since the polymer no longer flows after the gel point. Knowledge of structure-viscosity relationships can be useful in obtaining the optimum parameters for reactive processing operations, in providing a general understanding of the network formation mechanism, and in determining the final properties. In most curing systems, the reaction takes place at different kinetic stages : first slowly linear growth and then quick development of threedimensional network. Although there has been a considerable interest in rheological behavior and structural change in comparing to that of epoxy/amine systems, ${ }^{7-11}$ little progress has been made in elucidating the rheology structure relationships for epoxy/catalyst systems. Lee et al. ${ }^{12}$ developed a new class of Lewis acid catalysts, 1,2substituted-1,1-dimethylhydrazinium hexafluoroantimonates, and found that these salts serve as thermally latent cationic initiators in the curing and polymerization of glycidyl phenyl ether.

The purpose of this paper is to characterize a newly developed $N$-BQH catalysts with $N$-benzyl group containing quinoxaline salt in epoxy curing reactions and to 


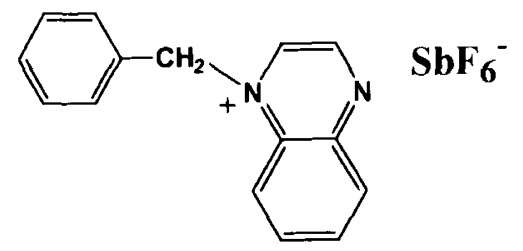

$\mathrm{N}-\mathrm{BQH}$

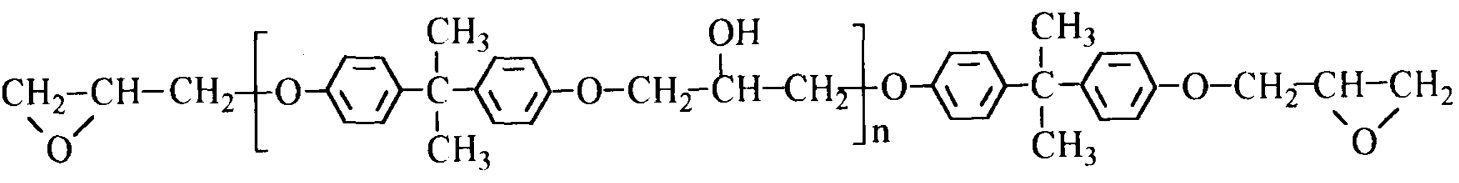

$\mathrm{n}=0.12-0.13$

\section{DGEBA}

Figure 1. The calculated chemical structure of the DGEBA and $N$-BQH.

obtain a detailed information concerning the reaction mechanism and variable dependence of rheological properties by using FT-IR, DSC, and dynamic shear measurements.

\section{EXPERIMENTAL}

\section{Materials}

The epoxy resin used in this study was diglycidylether of bisphenol A (DGEBA, YD 128 supplied from Kukdo Chem. Co. of Korea). The epoxide equivalent weight of DGEBA was $185-190 \mathrm{~g} / \mathrm{eq}$. and its density was $1.16 \mathrm{~g}$ $\mathrm{cm}^{-3}$ at $25^{\circ} \mathrm{C}$.

Synthesis of Catalyst. Into a $250 \mathrm{ml}$ flask equipped with a mechanical stirrer were put $6.50 \mathrm{~g}(50 \mathrm{mmol})$ of quinoxaline and $25.65 \mathrm{~g}(150 \mathrm{mmol})$ of benzyl bromide. The mixture reacted at room temperature for 11 days with continuous stirring. The white precipitate of benzylquinoxalinium bromide salt was collected by filtration and dissolved in $30 \mathrm{ml}$ distilled water. Next, 7.76 $\mathrm{g}(30 \mathrm{mmol})$ of $\mathrm{NaSbF}_{6}$ was added and the formed white product was filtered. And then recrystallization by using methanol made $9.30 \mathrm{~g}(40.7 \%)$ of pure white $N$-BQH. From DSC thermogram, the endothermic peak temperature of this material was $147.1^{\circ} \mathrm{C}$ (that is, the melting point).

The purity and the chemical structure of the product were confirmed by the elemental analysis, FT-IR, and the ${ }^{1} \mathrm{H}$ NMR as follows.

For FT-IR (KBr) ; 3098, 1514, 1359, 1073, 767, 667 $\mathrm{cm}^{-1}$.

For ${ }^{1} \mathrm{H}$ NMR (acetone- $d_{6}$ in ppm from tetramethylsilane);

Peaks for quinoxaline ring $(9.82-9.89,9.61-9.65$, $8.82-8.88,8.59-8.65,8.32-8.46 \mathrm{ppm})$.

Peaks for aromatic ring $(7.62-7.69,7.49-7.55 \mathrm{ppm})$.
Peaks for $-\mathrm{CH}_{2}-(6.66 \mathrm{ppm})$.

For elemental analysis ;

Calculated for $\mathrm{C}_{15} \mathrm{H}_{13} \mathrm{~N}_{2} \mathrm{SbF}_{6}$ : C, $39.39 \% ; \mathrm{H}, 2.84 \%$; N, 6.13 ;

Found for $\mathrm{C}_{15} \mathrm{H}_{13} \mathrm{~N}_{2} \mathrm{SbF}_{6}$ : C, 39.69\%; H, 2.86\%; N, $6.16 \%$.

DGEBA and obtained $N$-BQH structures are shown in Figure 1.

\section{Sample Preparation}

The required amount of the catalyst $(N-\mathrm{BQH})$ was accurately weighted into a $250 \mathrm{ml}$ beaker equipped with a mechanical stirrer and was dissolved in two folds of acetone. The required amount of epoxy (DGEBA) was added. The beaker containing the sample was stirred for $10 \mathrm{~min}$ and degassed for $60 \mathrm{~min}$ before measuring. The molar catalyst concentrations corresponded to epoxy/N-BQH ratios of $99.5: 0.5,99: 1,98: 2,97: 3$, and $95: 5$. The curing condition was $80^{\circ} \mathrm{C}$ for $1 \mathrm{~h}$ plus $160^{\circ} \mathrm{C}$ for $2 \mathrm{~h}$ and then $180^{\circ} \mathrm{C}$ for $2 \mathrm{~h}$ for post curing, respectively.

\section{Measurements}

DSC measurements were carried out with Du Pont DSC 910 thermal analyzer. The heating rate was $10^{\circ} \mathrm{C}$ $\mathrm{min}^{-1}$. And the scanning range was from $50^{\circ} \mathrm{C}$ to $330^{\circ} \mathrm{C}$.

The used FT-IR instrument was a Hartmann \& Braun Model Bomen MB 102 Spectrophotometer. The scan was from 400 to $4000 \mathrm{~cm}^{-1}$ and it required $40 \mathrm{~s}$ for one scan. Since the scan was conducted at high temperatures, a hot cell was used to mount the samples. A GrasedySpecac Temperature Controller (Model Eurotherm) was used along with heating elements and a thermocouple to control the temperature of the hot cell. A maximum of 20 scans per run were carried out.

The dynamic shear modulus at isothermal conditions were monitored by using the parallel plate geometry on 
Physica (Rheo Lab. MC 10). The disposable plates ( $\phi=50$ $\mathrm{mm}$ ) were pre-heated in the environmental chamber of the rheometer for approximately $10 \mathrm{~min}$ at setting temperatures before test. The gap between the plates and the frequency of oscillation mode were $0.5 \mathrm{~mm}$ and $5 \mathrm{~Hz}$, respectively. After loading the sample, the temperature of the chamber was equilibrated to setting temperature about $1 \mathrm{~min}$. The maximum operating temperature was fixed as $160^{\circ} \mathrm{C}$.

\section{RESULTS AND DISCUSSION}

\section{Thermal Behavior and FT-IR Measurements}

Catalysts are important in chemical reactions, since they decrease activation energies to accelerate the reactions. Catalysts that show no activity under normal condition but show activity by external stimulation are called "latent catalysis". Heating, photo-irradiation, pressure, magnetism, ultrasonic wave, electron beam, Xrays, and so on are the candidates of external stimulation. Heating and photo-irradiation are the most important for practical use because their lower cost and higher safety. Heating is more facile external stimulation than photo-irradiation for practical use since homogeneous heating of reaction mixtures can be easily attained. Homogeneous photo-irradiation is relatively difficult since the irradiation area depends on the irradiation source and reaction vessel. The most useful characteristic of latent catalyst is that they can control propagation step as well as initiation step of chemical reactions by external stimulations. Therefore, reaction temperature, time, and place can be conveniently selected by using latent catalyst. This concept of latent catalyst has been developed to "latent initiators" of polymerizations. Latent initiators can simplify the operation of the curing process, namely, one-pot curing system becomes possible by using latent initiators. But the information of only catalyst cured epoxy systems is very rare.

In this article, our recent researches on newly developed cationic latent initiators are described. We have synthesized benzyl quinoxalinium salt and examined polymerization of epoxide (DGEBA). Cationic polymerizations of this monomer could be initiated by $N-\mathrm{BQH}$ with heating to afford the corresponding polymer in satisfactory yields. Benzyl quinoxalium salt also acts as latent catalyst. The order of activity depends upon the nature of the counter anions $\left(\mathrm{SbF}_{6}{ }^{-}>\mathrm{PF}_{6}{ }^{-}>\mathrm{AsF}_{6}{ }^{-}>\mathrm{BF}_{4}{ }^{-}\right)$, and this order reflects the nucleophilicity of the counter anions. Arnold ${ }^{13}$ concluded that cationic catalysts with boron trifluoride in the presence of hydroxyl groups proceeds via a carbonium ion intermediate. This ion, in turn, reacts with a hydroxyl group from the resin, to give an alkoxide and regenerate the boron trifluoride. This is in keeping with the findings of Lee et al. ${ }^{14}$

The concentration of catalyst is a very important factor in catalytic curing of epoxy. Figure 2 shows dynamic DSC thermograms for the epoxy resins containing 0.5 , $1.0,2.0,3.0$, and $5.0 \mathrm{~mol} \%$ of $N$-BQH. The multimodal exothermic peaks of the DSC thermogram demonstrate that there are more than one type of reaction. $N-\mathrm{BQH}$ was proved to be an excellent thermally latent initiator for epoxy resins without any co-initiator. These results show similar behavior to those reported for epoxy-cured

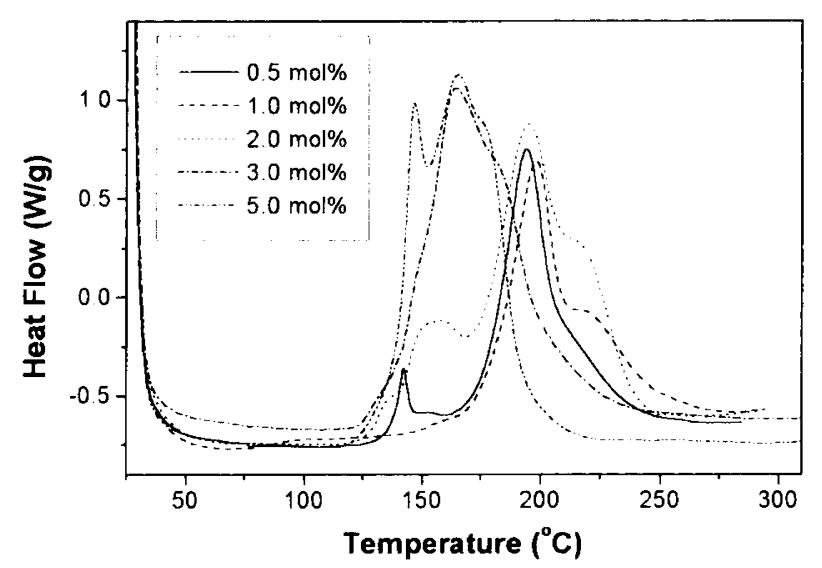

Figure 2. Dynamic DSC thermograms of the untreated samples (heating rate is $10^{\circ} \mathrm{C} \mathrm{min}^{-1}$ ).

systems by aliphatic sulfonium salts ${ }^{5,6}$ and aromatic pyrazinium salt. ${ }^{15}$ In general, the polymerization reaction of cationic epoxy system leads to a Lewis acid process. ${ }^{16} \mathrm{Gu}$ et al., ${ }^{5}$ who studied the diphenyliodonium hexafluoroarsenate/epoxy system, suggested that the two different curing reactions occur. Based on Gu's and Lee's suggestion ${ }^{15}$ and DSC results, we consider that two separate initiation reactions, (i) - (ii) and three propagation reactions (iii) - $(\mathrm{x})$ behave as shown in Figure 3 . The actual initiating species may be suggested to be a benzyl cation in the reaction (i) on the basis of the structure-activity relationship of the benzyl quinoxalinium salt. The formation of $\mathrm{H}^{+} \mathrm{SbF}_{6}{ }^{-}$in the reaction (ii) starts the ring opening polymerization by the Lewis acid process. Quinoxaline formed by decomposition of $N$-BQH attacks the propagating end in the last stage of the polymerization to increase the termination. The two small exothermic peaks in Figure 2 indicate the existence of two separated initiation processes which differ in reactivity. These findings are consistent with previous research of Lee et $a l .{ }^{15}$ These two small peaks may be an evidence of the reaction between epoxides and $N-\mathrm{BQH}$, and the reaction between epoxides and hydroxyl groups in epoxy chains, which comprise catalyst degradation reaction. Compared with DSC results of the sample with a higher catalyst concentration in Figure 2, the thermogram of 0.5 mol\% sample shows a single peak in the low temperature exothermic region. One explanation for this observation may be that the reaction between epoxides and hydroxyl groups in epoxy resins is negligible because of small amount of $N-B Q H$. From these results, we speculate that the gelation probably begins with the initiation reaction between epoxides and $N-\mathrm{BQH}$ or between hydroxyl groups in epoxy resin and $N-\mathrm{BQH}$. As the catalyst concentration of $N-\mathrm{BQH}$ increases, the availability of the radical to react with the epoxide in the initial stage of cure would be more pronounced and makes the main peak temperature shift to a lower value. This main peak seems to present three dimensional cross-linking reaction of etherification between the two epoxides. The total heat of polymerization also increases with an increase in the catalyst concentration of $N-\mathrm{BQH}$; this is due to the occurrence of more cross-linking units. The thermal characteristics of this system has been checked by the DSC. As catalyst concentration of $N-B Q H$ increases, the 


\section{Initiation}

(i)

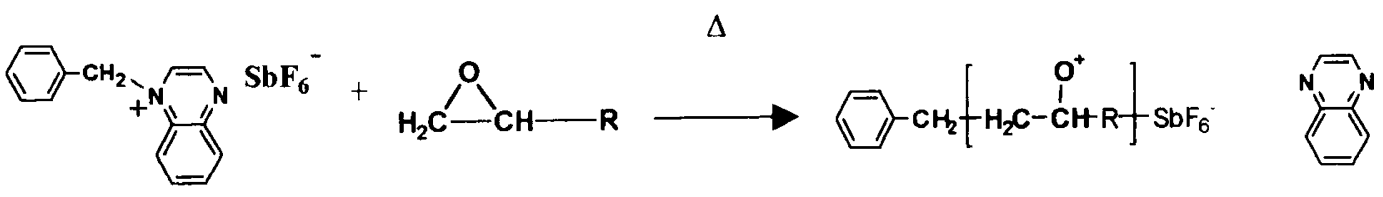

(ii)

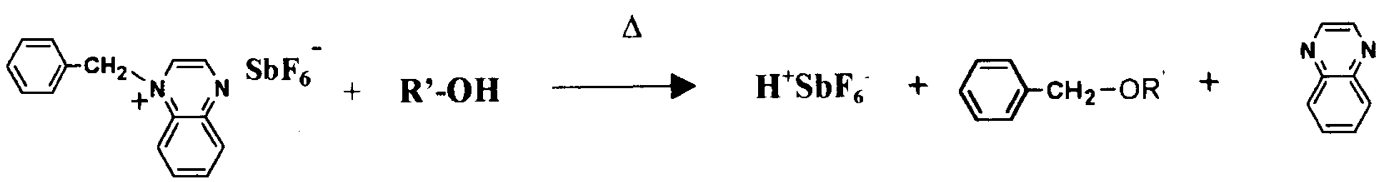

(where R'-OH represents hydroxyl groups in the epoxy resins)

\section{Propagation}

(iii)

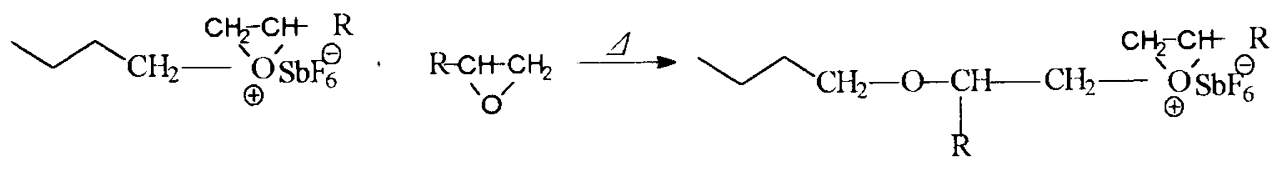

(iv)

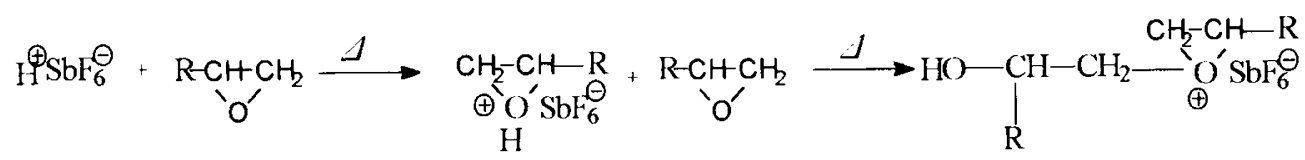

(v)

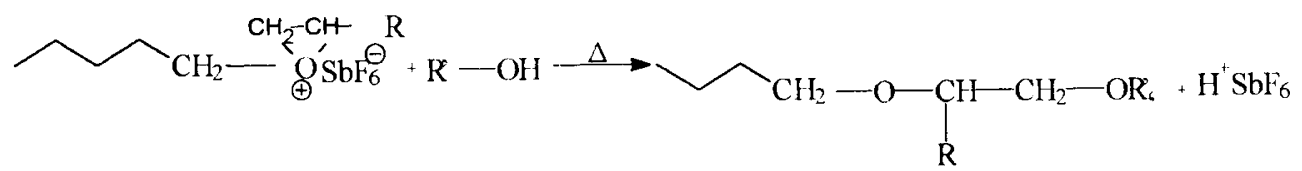

Figure 3. Suggested curing mechanism of the DGEBA/N-BQH systems.

third peak of thermogram decreases except for $0.5 \mathrm{~mol} \%$ sample. The glass transition temperature in this system increased with increasing catalytic concentration until $3.0 \mathrm{~mol} \%$ and then decreased. These results are summarized in Table $\mathrm{I}$.

In general, exothermic heat flow is proportional to the reaction rate of reactive groups such as epoxide and double bond. Reaction rate is proportional to the heat generation rate, $\mathrm{d} H / \mathrm{d} t$. Conversion rate, $\mathrm{d} a / \mathrm{d} t$, at time, $t$ and conversion can be expressed as follows ;

$$
\begin{gathered}
\frac{\mathrm{d} a}{\mathrm{~d} t}=\frac{(\mathrm{d} H / \mathrm{d} t)_{\mathrm{t}}}{\Delta H_{\mathrm{R}}} \\
a=\frac{\Delta H_{\mathrm{t}}}{\Delta H_{\mathrm{R}}}
\end{gathered}
$$

Where, the total reaction heat of reactive group, $\Delta H_{\mathrm{R}}$ can be replaced by dynamic exothermic heat, $\Delta H_{\text {dyn }}$ since $\Delta H_{\mathrm{R}}$, the sum of residual and isothermal exothermic heat is smaller than dynamic exothermic heat, $\Delta H_{\text {dyn }}$.

Finally we have obtained from Kamal's generalized expression $^{17}$ and the multiple linear regression method ${ }^{18}$ as follows : 
Table I. The thermal characteristic of DGEBA/BQH system

\begin{tabular}{|c|c|c|c|c|c|c|}
\hline \multirow{2}{*}{$\begin{array}{c}\text { Mol\% of } \\
\text { BQH }\end{array}$} & \multirow{2}{*}{$\begin{array}{c}\text { Glass } \\
\text { transition } \\
\text { temperature/ } \\
{ }^{\circ} \mathrm{C}^{\mathrm{a}}\end{array}$} & \multicolumn{4}{|c|}{ Main peak temperature in $\mathrm{DSC} /{ }^{\circ} \mathrm{C}$} & \multirow{2}{*}{$\begin{array}{l}\text { Total heat of } \\
\text { reaction } / \mathrm{Jg}^{-1}\end{array}$} \\
\hline & & 1 st & 2nd & 3 rd & 4 th & \\
\hline 0.5 & 54.5 & 142.3 & - & 193.9 & 208.6 & 293.4 \\
\hline 1.0 & 105.3 & - & 157.0 & 198.2 & 218.0 & 301.2 \\
\hline 2.0 & 134.4 & 139.1 & 157.0 & 194.9 & 210.7 & 484.4 \\
\hline 3.0 & 158.0 & 137.3 & 153.9 & 164.5 & 178.1 & 491.9 \\
\hline 5.0 & 135.7 & - & 147.0 & 165.5 & 174.8 & 491.9 \\
\hline
\end{tabular}

${ }^{a}$ Glass transition temperatures were obtained from second run of DSC at $10^{\circ} \mathrm{C} \mathrm{min}^{-1}$.

$$
\begin{gathered}
\ln \left(\frac{\mathrm{d} a}{\mathrm{~d} t}\right)=\ln \left(k_{1}+k_{2} \cdot a^{m}\right)+n \cdot \ln (1-\alpha) \\
\ln \left[\left(\frac{\mathrm{d} a}{\mathrm{~d} t}\right) /(1-a)^{n}-k_{1}\right]=\ln k_{2}+m \cdot \ln \alpha \\
\ln \left[\left(\frac{\mathrm{d} a}{\mathrm{~d} t}\right) /\left(k_{1}+k_{2} a^{m}\right)\right]=n \cdot \ln (1-a)
\end{gathered}
$$

Usually, the constant $k_{1}$ was graphically calculated as the initial reaction rate at $\alpha=0$, given by the intercept of the conversion rate-fractional conversion plot. A linear plot of the left-hand side of eq 3 against $\ln (1-a)$ would yield the reaction order, $n$ as the slope. By using this calculated value of $n$ in the eq 4, we could also obtain $\mathrm{m}$ as the slope and $k_{2}$ as the intercept from a linear plot of the left-hand side of eq 4 against $\ln \alpha$. As described previously, the exact reaction orders and constants can be graphically obtained from the curve fitting method by reducing the erratic values between before and after iterations.

Figure 4 indicates (a) the isothermal reaction rate and (b) conversion curves of $160^{\circ} \mathrm{C}$ as a function of cure time for $N$-BQH/DGEBA system with different catalyst concentrations. The isothermal technique as outlined by Prim $^{19}$ in this study exploits the ability of the DSC to monitor simultaneously the rate of reaction $(\mathrm{d} a / \mathrm{d} t)$ and conversion $(\alpha)$ over the entire course of reaction. The general procedure for obtaining isothermal scans involved allowing the DSC cell to equilibrate at the isothermal temperature, quickly transferring the sample to the cell, and allowing the run to continue until no more reaction was detectable as indicated by an equilibrium heat flow value being attained $(\mathrm{d} H / \mathrm{d} t=0)$.

For all the samples with various catalyst concentrations, Figure 4 a presents that the peak value increases and shifts to a shorter time with increasing catalyst concentrations: this means that the curing reaction proceeds through auto-catalytic mechanism. Figure $4 \mathrm{~b}$ shows that the fractional conversion for the sample with a higher catalyst concentration reaches a plateau value in a shorter time compared to the other. The fractional conversion increases with increasing catalyst concentration until $3.0 \mathrm{~mol} \%$ : that is, the final conversion for the excess concentration of catalyst of $5.0 \mathrm{~mol} \%$ sample has a lower value than that for the $3.0 \mathrm{~mol} \%$ sample. The former has the higher glass transition temperature than the latter as shown in Table I. The conversion is in the range of $69-89 \%$.
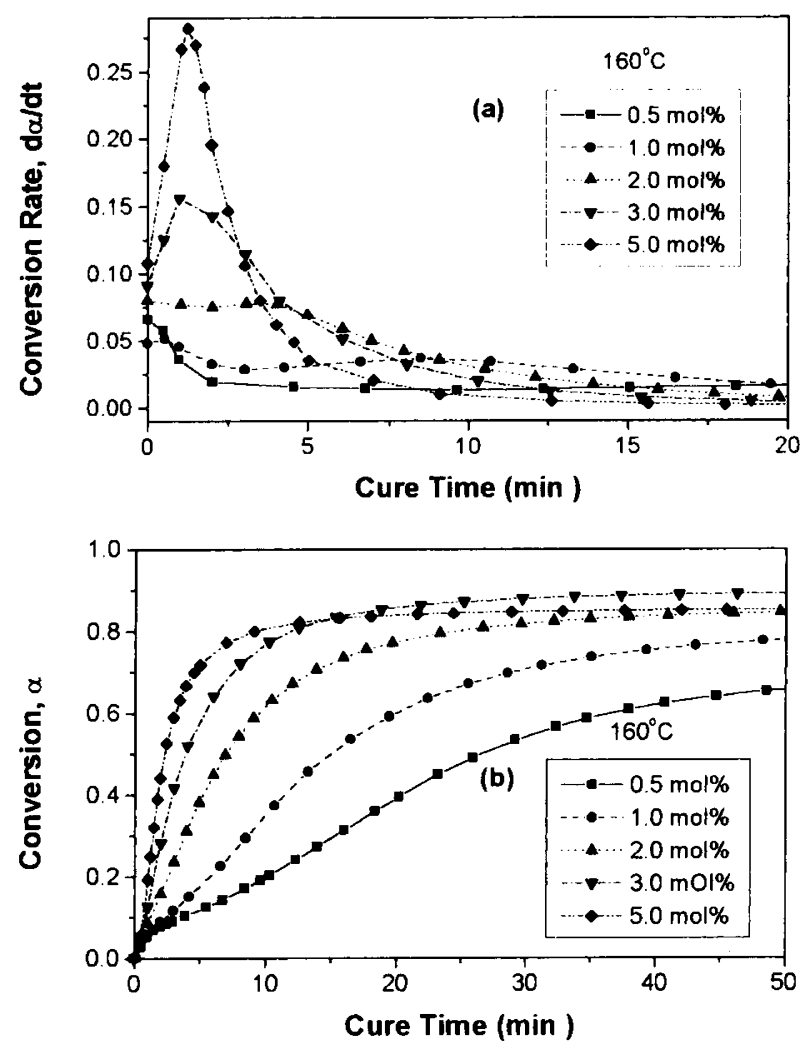

Figure 4. Conversion rate and Conversion of DGEBA/N-BQH system obtained from isothermal DSC results as a function of time at $160^{\circ} \mathrm{C}:$ (a) $\mathrm{d} a / \mathrm{d} t$; (b) $a$.

Figure 5 presents a series of reaction rate curves as a function of fractional conversion for $N$-BQH/DGEBA system with different catalyst concentrations and isothermal temperatures. The results reveal that the curing reactions proceed through autocatalytic mechanism with maximum conversion rate in conversion range of $2-32 \%$. As the catalyst concentration of $N-\mathrm{BQH}$ and isothermal curing temperature increase, the conversion rate increases.

The temperature dependence of rate constant can be determined with Arrhenius equation. The kinetic parameter of $k_{1}, k_{2}, m, n$ depending on the concentration and the curing temperature were calculated by fitting the experimental data to eq 3,4 , and $5 .^{20}$ The isothermal experimental data for the sample with a fixed catalyst concentration are summarized in Table II.

The average of reaction constant, $k_{2}$ known as related to auto-catalytic reaction always has a higher value than the average of reaction constant, $k_{1}$ known as related to initial reaction between the epoxide and catalyst except for 0.5 and $2.0 \mathrm{~mol} \%$ samples. It may come from the good reactivity of hydroxyl group generated by ring opening of autocatalytic reaction. The activation energies $\left(E_{1}, E_{2}\right)$ can be obtained as a slope from a linear plot of lnk against $1 / T$ in Arrhenius reaction equation as shown in Figure 6 . The activation energy, $E_{1}$ tends to increase with increasing catalyst concentration as shown in Figure $6 \mathrm{a}$. The activation energy, $E_{2}$ increased with an increase of the catalyst concentration except for $2.0 \mathrm{~mol} \%$ sample which has higher values than $3.0 \mathrm{~mol} \%$ sample as shown in Figure $6 \mathrm{~b}$. These results indicate that the level of catalyst concentration has a significant effect on 

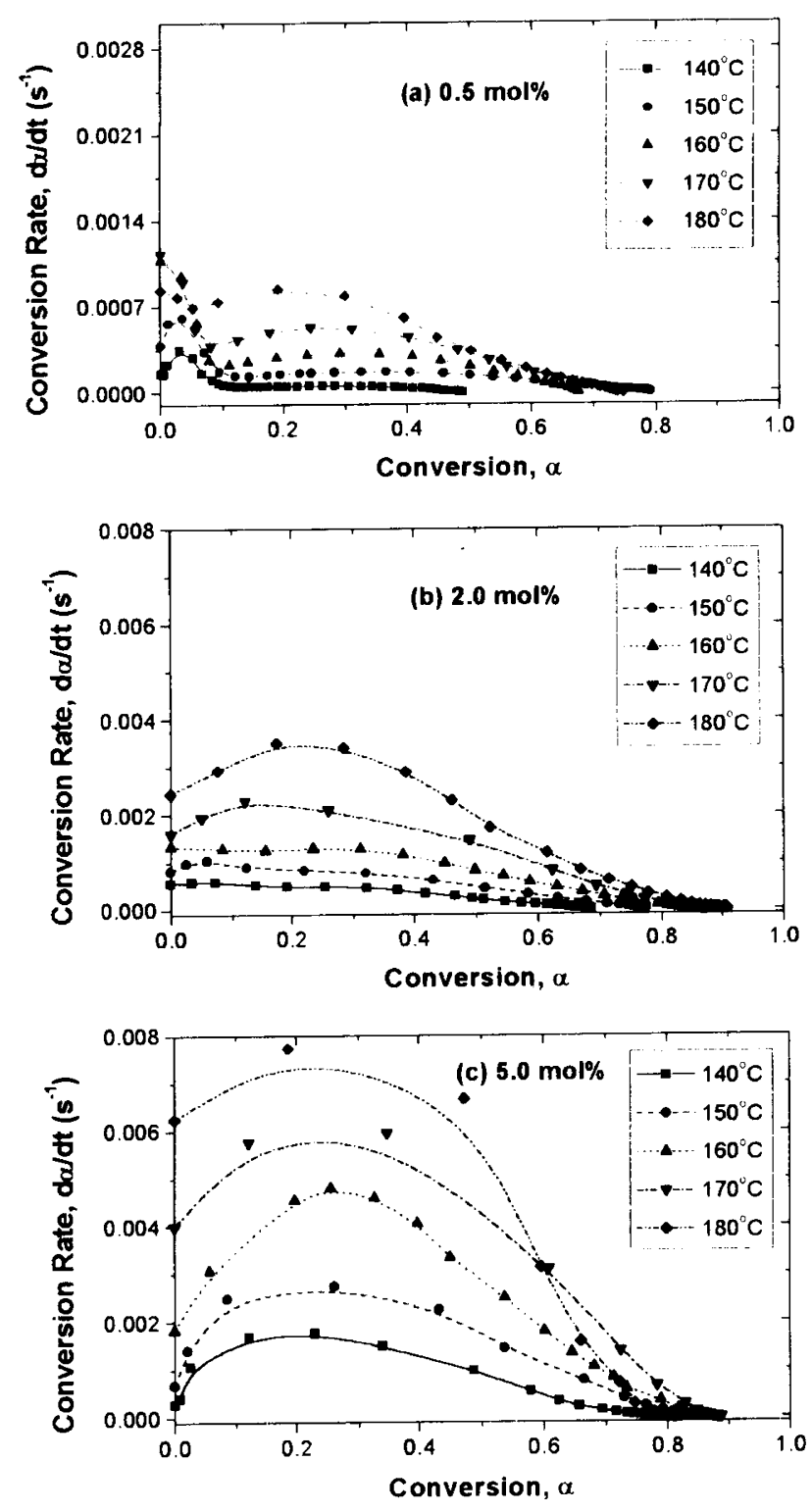

Figure 5. Conversion rate $v s$. conversion plots of DGEBA $/ N$ $\mathrm{BQH}$ system obtained from isothermal DSC results at different temperature : (a) 0.5 ; (b) 2.0 ; (c) $5.0 \mathrm{~mol} \%$.

activation energy. The reactivity ratios of $\ln \left(k_{2} / k_{1}\right)$ for the catalyst concentration is in the range of $0.2-4.1$ as shown in Figure $6 \mathrm{c}$. The most interesting phenomena in this system are that there are different slopes at different isothermal cure temperature except for $2.0 \mathrm{~mol} \%$ sample : the $0.5,1,3$, and 5 mol\% samples cured at a higher temperature than $160^{\circ} \mathrm{C}$ have higher values of slopes than those at the temperature below $160^{\circ} \mathrm{C}$. It means that the samples experience a critical change at the isothermal cure temperature of $160^{\circ} \mathrm{C}$.

The reaction order was determined by averaging values of all isothermal experimental data. The sum of the exponent factors, total reaction order $(m+n)$, of this system showed a tendency to increase with increasing catalyst concentration except for 0.5 and $1.0 \mathrm{~mol} \%$ sample as shown in Figure 7. The total reaction order in these systems presenting more than 2.7 is greater than that of amine/epoxy system which is known as about $2 .{ }^{21}$ This catalyst/epoxy resin system seems to contain the more
Table II. Kinetic parameters of DGEBA/ $N-B Q H$ system following autocatalytic curing reaction

\begin{tabular}{|c|c|c|c|c|c|c|}
\hline$\frac{\text { Contents }}{\text { mol\% }}$ & $\frac{\text { Temperature }}{{ }^{\circ} \mathrm{C}}$ & $m$ & $n$ & $\begin{array}{c}\begin{array}{c}k_{1} \\
\left(\times 10^{-3}\right)\end{array} \\
\mathrm{s}^{-1}\end{array}$ & $\begin{array}{c}\begin{array}{c}k_{2} \\
\left(\times 10^{-2}\right)\end{array} \\
\mathrm{s}^{-1}\end{array}$ & $\begin{array}{c}\begin{array}{c}\text { Reaction rate } \\
\text { constants } k_{1}, k_{2}\end{array} \\
\mathrm{~s}^{-1}\end{array}$ \\
\hline \multirow{5}{*}{0.5} & 150 & 2.7 & 2.7 & 0.39 & 0.37 & \multirow{2}{*}{$\begin{array}{c}k_{1}=3.62 \times 10^{i} \exp \\
(-39000 / R T)\end{array}$} \\
\hline & 160 & 2.4 & 6.1 & 1.08 & 0.70 & \\
\hline & 170 & 2.2 & 4.5 & 1.13 & 0.73 & \multirow{3}{*}{$\begin{array}{c}k_{2}=6.59 \times 10^{5} \exp \\
(-66700 / R T)\end{array}$} \\
\hline & 180 & 1.6 & 3.6 & 0.84 & 1.39 & \\
\hline & Average & 2.2 & 4.2 & 0.86 & 0.80 & \\
\hline \multirow{5}{*}{1.0} & 150 & 2.1 & 2.8 & 0.49 & 0.71 & \multirow{5}{*}{$\begin{array}{c}k_{1}=8.91 \times 10^{2} \exp \\
(-50400 / R T) \\
k_{2}=1.08 \times 10^{10} \exp \\
(-98600 / R T)\end{array}$} \\
\hline & 160 & 2.3 & 3.0 & 0.80 & 1.27 & \\
\hline & 170 & 2.2 & 3.3 & 1.13 & 3.25 & \\
\hline & 180 & 1.7 & 3.9 & 1.20 & 3.75 & \\
\hline & Average & 2.1 & 3.3 & 0.91 & 2.25 & \\
\hline \multirow{5}{*}{2.0} & 150 & 0.4 & 1.6 & 0.82 & 0.10 & \multirow{5}{*}{$\begin{array}{c}k_{1}=1.07 \times 10^{4} \mathrm{exp} \\
(-57600 / R T) \\
k_{2}=3.06 \times 10^{19} \mathrm{exp} \\
(-183000 / R T)\end{array}$} \\
\hline & 160 & 0.6 & 1.5 & 1.33 & 0.17 & \\
\hline & 170 & 0.8 & 2.1 & 1.61 & 0.85 & \\
\hline & 180 & 1.1 & 2.8 & 2.44 & 2.72 & \\
\hline & Average & 0.7 & 2.0 & 1.55 & 0.96 & \\
\hline \multirow{5}{*}{3.0} & 150 & 0.6 & 2.1 & 1.07 & 0.44 & \multirow{5}{*}{$\begin{array}{c}k_{1}=7.32 \times 10^{5} \exp \\
(-71800 / R T) \\
k_{2}=4.68 \times 10^{17} \exp \\
(-162600 / R T)\end{array}$} \\
\hline & 160 & 0.8 & 2.5 & 1.52 & 1.11 & \\
\hline & 170 & 1.0 & 2.8 & 2.58 & 2.87 & \\
\hline & 180 & 1.3 & 3.7 & 3.78 & 8.34 & \\
\hline & Average & 0.9 & 2.8 & 2.24 & 3.19 & \\
\hline \multirow{5}{*}{5.0} & 150 & 0.7 & 2.4 & 0.68 & 1.33 & \multirow{2}{*}{$\begin{array}{c}k_{1}=1.33 \times 10^{12} \exp \\
(-123600 / R T)\end{array}$} \\
\hline & 160 & 1.0 & 2.8 & 1.83 & 3.72 & \\
\hline & 170 & 1.4 & 3.5 & 4.00 & 12.1 & \multirow{3}{*}{$\begin{array}{c}k_{2}=1.66 \times 10^{21} \exp \\
(-187500 / R T)\end{array}$} \\
\hline & 180 & 1.7 & 4.6 & 6.24 & 38.5 & \\
\hline & Average & 1.2 & 3.3 & 3.19 & 13.7 & \\
\hline
\end{tabular}

complex kinetic reaction mechanism than amine/epoxy system. In amine/epoxy system, epoxy compound reactions with primary and secondary amines occur competitively in the auto-acceleration and auto-inhibition reactions from the kinetic point of view. ${ }^{5,6,15,16}$ But in cationic catalytic epoxy system, the epoxy-oligomer curing with catalyst has an auto-catalytic character without any inhibition reaction due to the accumulation of hydroxyl groups during the reaction.

Figure 8 shows the infrared spectrum of DGEBA $/ N$ $\mathrm{BQH}$ systems during the isothermal curing at $160^{\circ} \mathrm{C}$. To discuss the results from FT-IR experiments, it is necessary to assign the peak. There have been a large number of investigations using FT-IR for amine/epoxy systems. ${ }^{21-23}$ The most common reference band is the $\mathrm{C}-\mathrm{H}$ stretch associated with the aromatic hydrogens in the monomer chain backbone $\left(1510 \mathrm{~cm}^{-1}\right)$, since it has a very strong absorption and is not involved in any of the cure reactions. Ether bands are usually found between 1000 and $1200 \mathrm{~cm}^{-1}$. A hydroxyl absorption peak occurs at $3500 \mathrm{~cm}^{-1}$. An epoxide band occurs at $913 \mathrm{~cm}^{-1}$. In the sample with $0.5 \mathrm{~mol} \%$ of catalyst, the epoxide peak intensity gradually decreases with an increasing curing time even though the small peak remains for the cured sample after $1 \mathrm{~h}$ due to the residue of epoxide groups. On the contrary, as increasing the catalyst concentration of $N$-BQH, the peak intensity of epoxide sharply decreases 

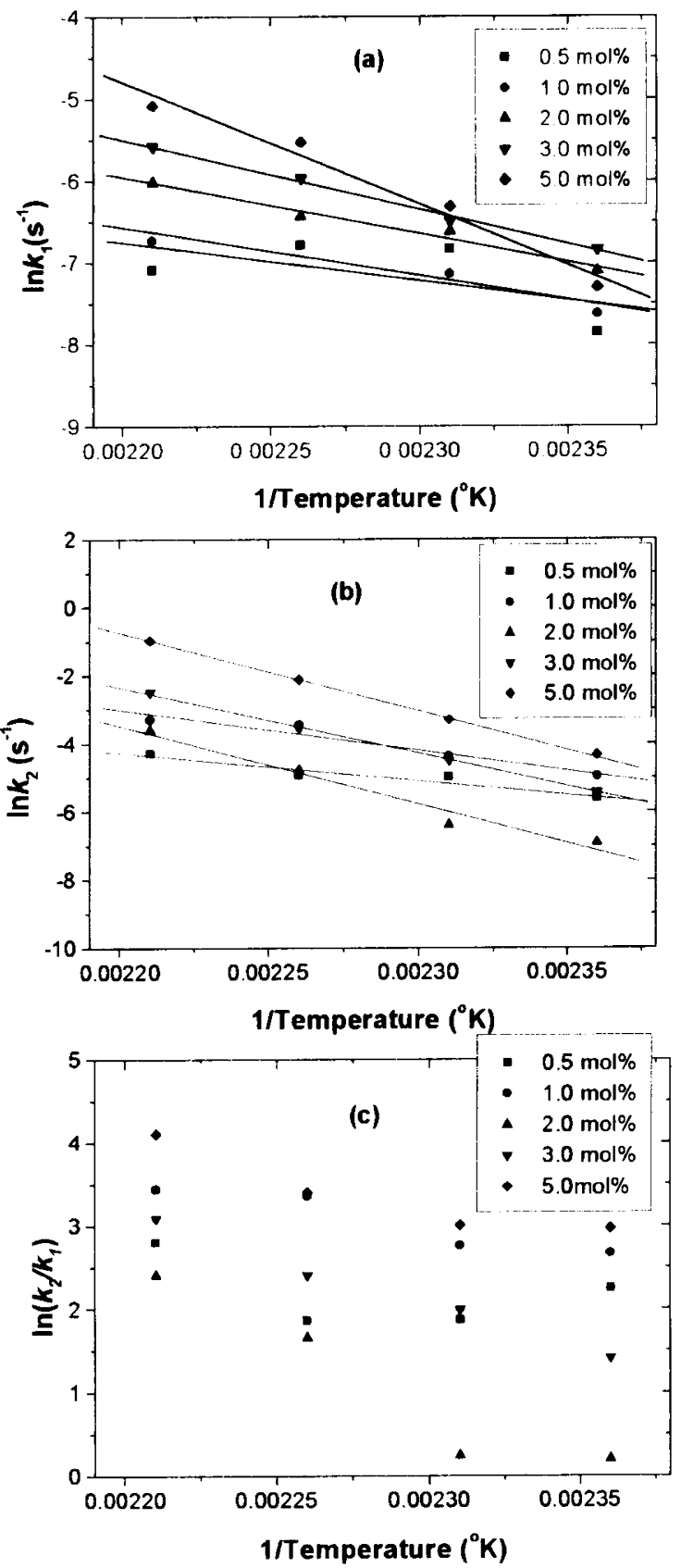

Figure 6. Arrhenius plots of initial and autocatalytic reaction rate and reactivity ratio of DGEBA/N-BQH system : (a) $\operatorname{lnk}_{1}$; (b) $\ln k_{2} ;(\mathrm{c}) \ln \left(k_{2} / k_{1}\right)$.

with a curing time, and then the epoxide peak almost disappears after $1 \mathrm{~h}$ of cure. The spectroscopy of hydroxyl-containing compounds is frequently complicated by the occurrence of hydrogen bonding. For the 5 $\mathrm{mol} \%$ sample, the increase of $\mathrm{O}-\mathrm{H}$ peak intensity with curing time suggests that the curing process may lead to more production of $\mathrm{O}-\mathrm{H}$ at a high catalyst concentration of $N$-BQH. ${ }^{21}$ The $\mathrm{C}-\mathrm{O}$ peaks $\left(1100 \mathrm{~cm}^{-1}\right)$ increase with curing time. This behavior reveals the production of $\mathrm{C}-\mathrm{O}$ peak by the propagation reaction of epoxide groups and the additional reaction of epoxide at the elevated temperature.

\section{Rheological Behavior in Dynamic Shear Measurements}

Rheological properties such as dynamic modulus or

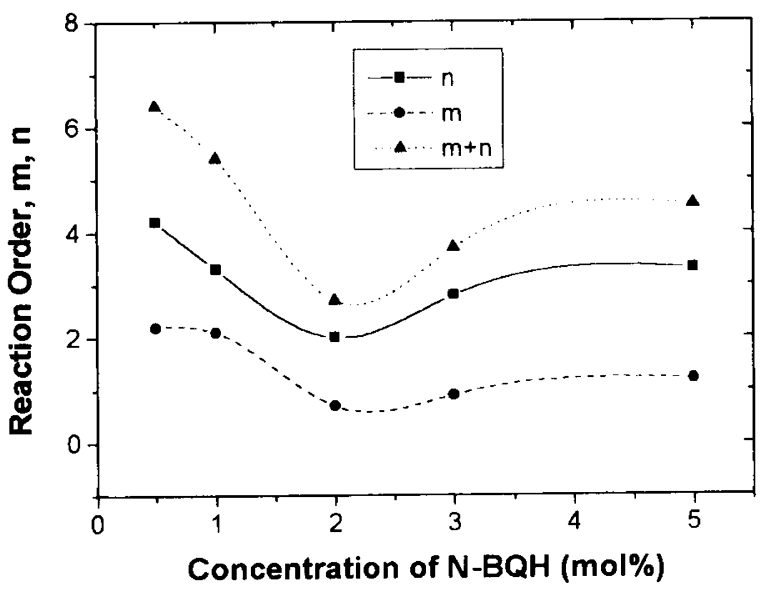

Figure 7. Kinetic parameters, $m$ and $n$ as a function of concentration of $N-\mathrm{BQH}$ for the DGEBA $/ N-\mathrm{BQH}$ systems.
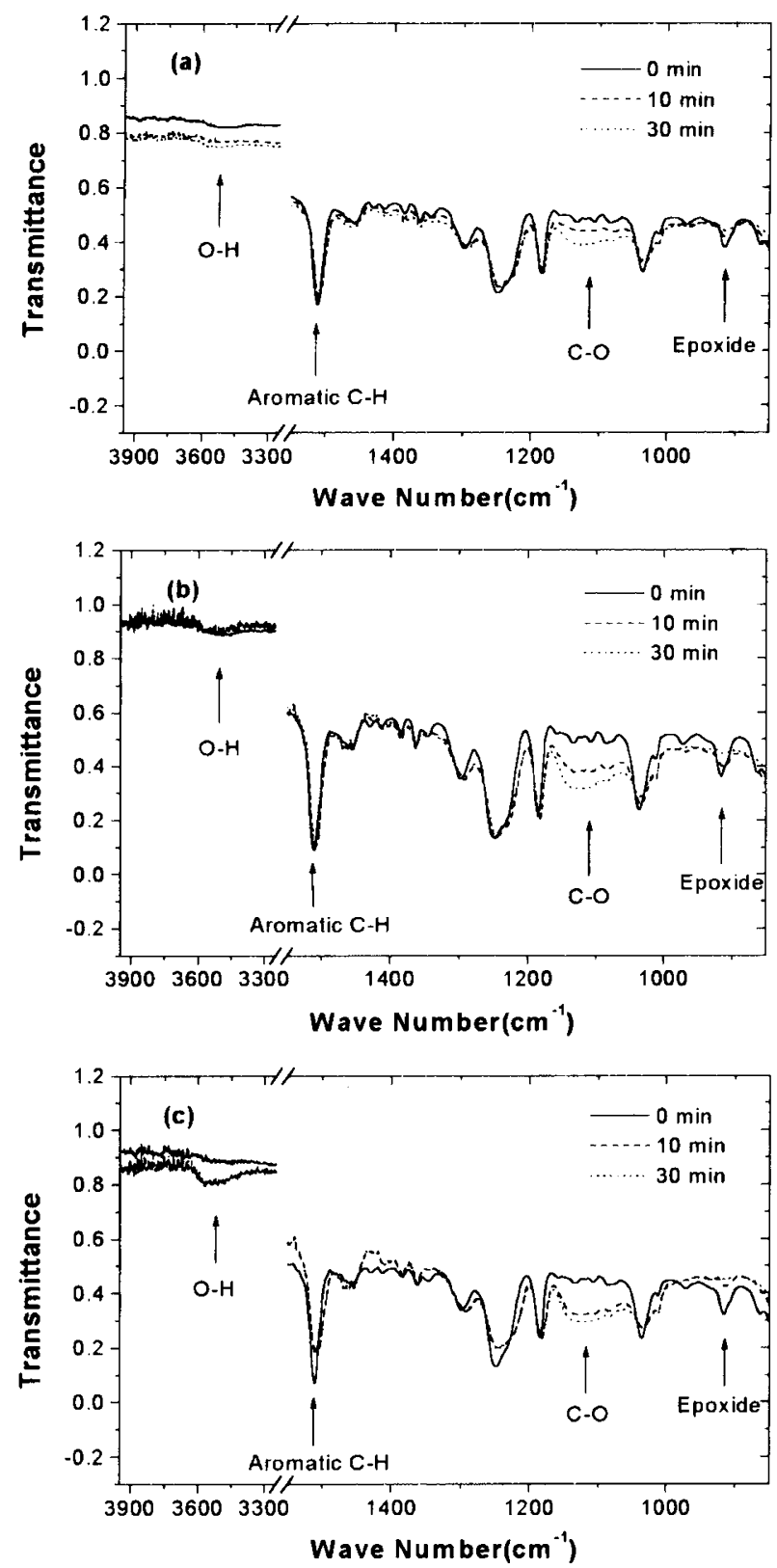

Figure 8. FT-IR spectrum vs. time during cure at $160^{\circ} \mathrm{C}$ for DGEBA $/ N$-BQH system : (a) $0.5 \mathrm{~mol} \%$; (b) $2.0 \mathrm{~mol} \%$; (c) $5.0 \mathrm{~mol}$ $\%$.

Polym. J., Vol. 32, No. 3, 2000 

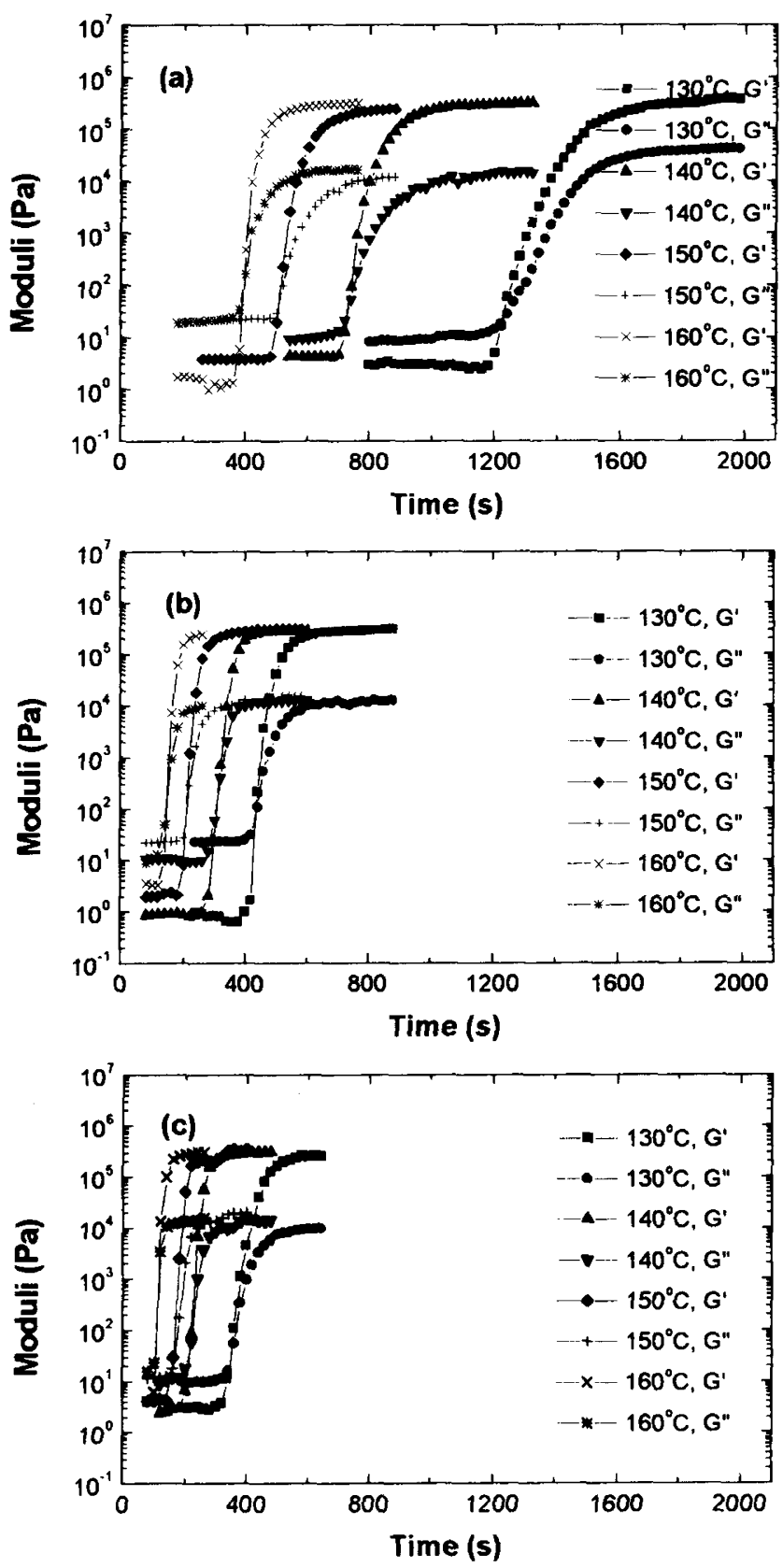

Figure 9. Moduli profiles of various isothermal temperature for DGEBA $/ N-B Q H$ system : (a) $0.5 \mathrm{~mol} \%$; (b) $3.0 \mathrm{~mol} \%$; (c) $5.0 \mathrm{~mol}$ $\%$.

viscosity have some correlation with physical and mechanical properties in curing process, in which the storage modulus $\left(G^{\prime}\right)$ and loss modulus $\left(G^{\prime \prime}\right)$ relate to elastic and viscosity properties in materials, respectively. ${ }^{24}$ In order to analyze the influence of temperature on the gel point, which is defined as a transition state between liquid and solid phases, ${ }^{25,26}$ the dynamic shear moduli were monitored by using the parallel plate geometry. Modulus profiles obtained from the isothermal cure of $0.5 \mathrm{~mol} \%$ sample are reported in Figure 9. The gel time decreases with increasing temperature. It is possible that the elevation of curing temperature accelerates the initiation reaction. In the initial stage of reaction, the molecular weight slowly increases as a consequence of the chain growth of monomer. As the polymerization goes on, there is a strong increase of storage modulus near the gel point due to the progressive formation of a 3 dimensional polymeric network. The gel time may be obtained from the point at which the storage and loss modulus curves meet each other (i.e., the time when the damping factor reaches 1). ${ }^{8}$ Results of the gel times obtained from Figure 9 are presented in Figure 10. Oyanguren et $a l .{ }^{27}$ reported that cross-linking activation energy was obtained by measuring the gel times at various temperatures. Network structure can be expressed as a function of conversion and the dynamic reaction eq 10 produced by integrating eq 9 as follows ;

$$
\begin{gathered}
\frac{\mathrm{d} a}{\mathrm{~d} t}=k \cdot f(a) \\
k=A \cdot \exp (-E / R T) \\
\frac{\mathrm{d} a}{f(a)}=A \cdot \exp (-E / R T) \cdot \mathrm{d} t \\
\ln t_{\mathrm{c}}=\left[\ln \left(\int_{0}^{a c} \frac{\mathrm{d} a}{f(a)}\right)-\ln A\right]+E_{\mathrm{c}} / R T
\end{gathered}
$$

Assuming that the conversion of the gel point, $a_{\mathrm{c}}$, has no interaction with temperature and its value is constant, the gel time, $t_{c}$, can be described by the following Arrhenius expression $^{28}$ :

$$
\ln t_{\mathrm{c}}=\frac{E_{\mathrm{c}}}{R T}+C
$$

where, $E_{\mathrm{c}}$ : cross-linking activation energy, $R:$ gas constant, $T$ : cure temperature, $C$ : constant. This assumption is confirmed by the linear behavior observed in Figure 10. Table III summarizes the calculated results on cross-linking activation energies based on eq 10. The activation energies obtained for $0.5,2$, and $5 \mathrm{~mol} \%$ samples are $56.9,56.8$ and $56.4 \mathrm{~kJ} \mathrm{~mol}^{-1}$, respectively. The values of activation energy are approximately the same for all the catalyst concentrations, which indicates that the overall reaction mechanisms are nearly the same. These findings are in substantial agreement with those of Lee et al. ${ }^{15}$ The activation energies show lower values than the other systems previously reported which have $78 \mathrm{~kJ} \mathrm{~mol}^{-1}$ for the DICY/brominated epoxy, ${ }^{8}$ and 101 $\mathrm{kJ} \mathrm{mol}^{-1}$ for the diphenyliodonium hexafluoroarsenate/ cycloaliphatic epoxy. ${ }^{5}$

Figure 11 indicates the relationship between the damping factor and $N$-BQH catalyst concentration. The damping factor immensely decreases with the curing time near the gel point where $\tan \delta$ is 1 . The shoulder shifts toward a shorter curing time as the catalyst concentration increases. The curves of $\tan \delta$ after gel point showed fluctuating (or damping) behavior with curing time, especially in the case of $5.0 \mathrm{~mol} \%$ sample at the temperature of $150^{\circ} \mathrm{C}$. This damping behavior may indicate different in various catalyst concentrations and isothermal temperatures. After gel point, the $\tan \delta$ of 0.5 mol\% sample at the temperature of $130^{\circ} \mathrm{C}$ in Figure $11 \mathrm{a}$ has a higher value than those of $0.5,2.0$, and $5.0 \mathrm{~mol} \%$ sample at isothermal cure temperatures of $140^{\circ} \mathrm{C}, 150^{\circ} \mathrm{C}$, and $160^{\circ} \mathrm{C}$ in Figures $11 \mathrm{~b}-\mathrm{d}$. But the $\tan \delta$ of $0.5,2.0$, and $5.0 \mathrm{~mol} \%$ sample at the temperatures of $140^{\circ} \mathrm{C}, 150$ ${ }^{\circ} \mathrm{C}$, and $160^{\circ} \mathrm{C}$ have similar values. It may suggest that 


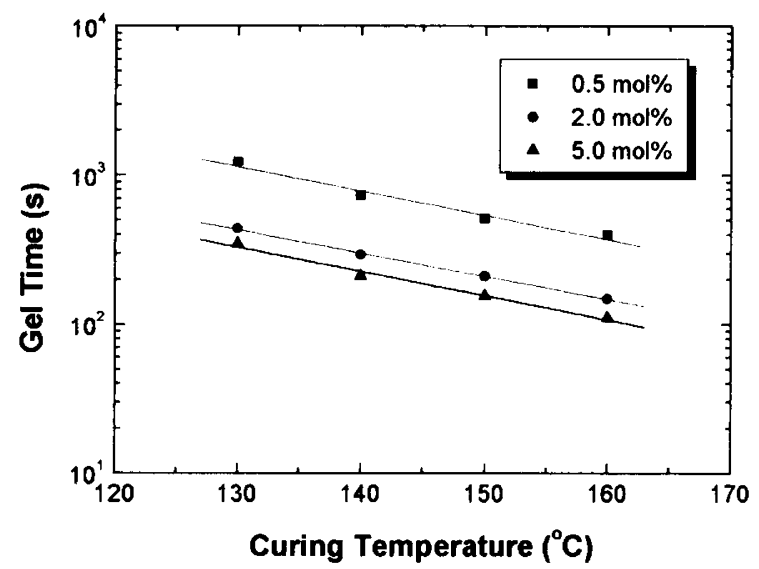

Figure 10. Arrhenius plot of gel times at constant frequency (5 $\mathrm{Hz}$ ).

Table III. Cross-linking activation energies, $E_{\mathrm{c}}$, obtained by gel times and cure temperatures

\begin{tabular}{ccccc}
\hline $\begin{array}{c}\mathrm{mol} \% \\
\text { of BQH }\end{array}$ & $1 / T / \mathrm{K}$ & $\ln t_{\mathrm{c}}$ & $\frac{E_{\mathrm{c}}}{\mathrm{kJ} \mathrm{mol}^{-1}}$ & $\begin{array}{c}\text { Correlation } \\
\text { factor }\end{array}$ \\
\hline & 0.00248 & 7.11 & & \\
0.5 & 0.00242 & 6.59 & & \\
& 0.00236 & 6.23 & 56.9 & 0.99602 \\
& 0.00231 & 5.97 & & \\
& 0.00226 & 5.54 & & \\
\hline \multirow{3}{*}{2.0} & 0.00254 & 6.61 & & \\
& 0.00248 & 6.08 & & \\
& 0.00242 & 5.68 & 56.8 & 0.99666 \\
& 0.00236 & 5.34 & & \\
& 0.00231 & 5.00 & & \\
& 0.00254 & 6.26 & & \\
& 0.00248 & 5.85 & & \\
& 0.00242 & 5.35 & 56.4 & 0.99765 \\
& 0.00236 & 5.04 & & \\
& 0.00231 & 4.70 & & \\
\hline
\end{tabular}

the insufficient catalyst at the lower cure temperature give very complex, may be harmful, influence to develop three dimensional networks during the solidification process.

\section{CONCLUSION}

The catalyst prepared in this work acts as a thermally latent cationic initiator in the curing reaction of epoxy resin. The total reaction order has a greater value than 2.7 while the amine/epoxy system has the order of 2.0 . This result reveals that this catalyst/epoxy resin system seems to contain a more complex kinetic reaction mechanism than the amine/epoxy system.

By using the Arrhenius type equation, the calculated cross-linking activation energies $\left(E_{\mathrm{c}}\right)$ were in the range of 56 to $57 \mathrm{~kJ} \mathrm{~mol}^{-1}$. These results indicate that the overall curing mechanisms are nearly the same. The damping factor curves after gel point showed fluctuating behavior with curing time, especially in the case of 5.0 mol\% sample. After gel point, the loss tangent of $0.5 \mathrm{~mol}$
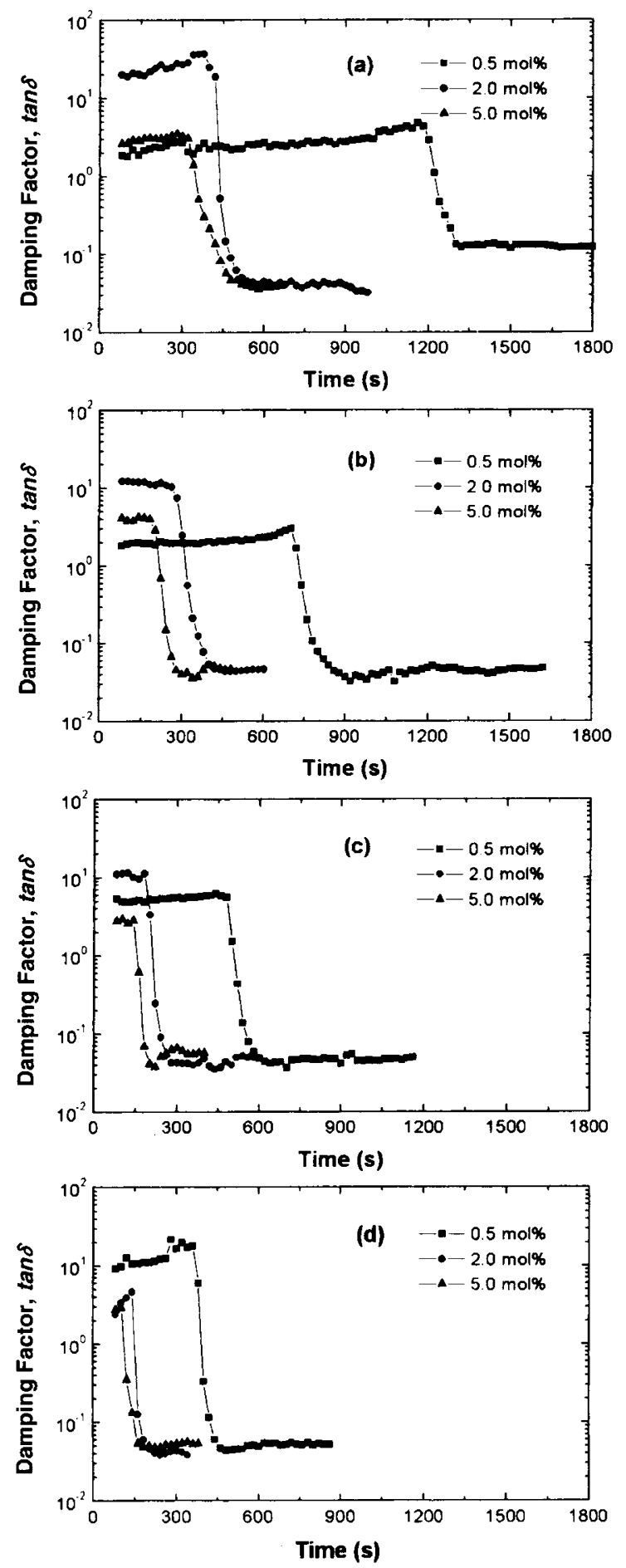

Figure 11. Damping factor profiles of various catalyst concentrations for $\mathrm{DGEBA} / N-\mathrm{BQH}$ system: (a) $130^{\circ} \mathrm{C}$; (b) $140^{\circ} \mathrm{C}$; (c) 150 ${ }^{\circ} \mathrm{C}$; (d) $160^{\circ} \mathrm{C}$.

$\%$ sample at the temperature of $130^{\circ} \mathrm{C}$ has a higher value than those of all the samples at different higher cure temperatures.

\section{REFERENCES}

1. J. V. Crivello and J. L. Lee, Macromolecules, 14, 1141 (1981).

2. I. I. Abu-Abdoun and A. Ali, Eur. Polym. J., 29, 1439 (1993).

3. S. P. Pappas and L. H. Hill, J. Coat. Technol, 53, 43 (1981).

4. T. Endo, A. Kikkawa, H. Uno, and H. Sato, J. Polym. Sci., Polym. Lett. Ed., 27, 73 (1989).

5. J. Gu, S. C. Narang, and E. M. Pearce, J. Appl. Polym. Sci., 
30, 2997 (1985).

6. K. Morio, H. Murase, and H. Tsuchiya, J. Appl. Polym. Sci., 32, 5727 (1986).

7. P. G. Babayevsky and J. K. Gillham, J. Appl. Polym. Sci., 17, 2067 (1973).

8. C. M. Tung and P. J. Dynes, J. Appl. Polym. Sci., 27, 569 (1982).

9. D. Adolf, J. E. Martin, and J. P. Wilcoxon, Macromolecules, 23, $527(1990)$

10. J. J. Imaz, N. Markaide, M. J. Jurado, M. A. Corcuera, and I. Mondragon, Eur. Polym. J., 28, 299 (1992).

11. P. J. Halley and M. E. Mackey, Polym. Eng. Sci., 36, 593 (1996).

12. S. B. Lee, Y. S. Park, K. W. Lee, and T. Endo, Chem. Lett., 17, 287 (1995)

13. R. J. Arnold, Mod. Plastics, 41, 149 (1964)

14. L. H. Lee, J. W. Pankey, and J. P. Helschen, J. Polym. Sci., 3 A, 2955 (1965).

15. Y. C. Kim, S. J. Park, and J. R. Lee, Polym. J., 29, 759 (1997).

16. H. F. Mark, R. M. Bikales, C. G. Overberger, G. Menges, and J. I. Kroschwitz, Encyclopedia of Polym. Sci. Eng., Second Ed., 6, 340 (1986).
17. M. R. Kamal, Polym. Eng. Sci, 14, 23 (1974)

18. J. P. Eloundou, M. Feve, D. Harran, and J. P. Pascoult, Angew. Makromol. Chem., 230, 13 (1995).

19. B. Prim, "Thermal Characterization of Polymeric Materials", E. A. Turi, Ed., Academic Press, New York, N.Y., 1981, Chapter 5 .

20. L. Barral, J. Cano, A. J. Lopez, P. Nogueira, and C. Ramirez, J. Appl. Polym. Sci., 56, 1029 (1995)

21. X. Wang and J. K. Gillham, J. Appl. Polym. Sci., 43, 2267 (1991).

22. Y. G. Lin, H. Sautereau, and J. P. Pascault, J. Polym. Sci., Polym. Chem. Ed., 24, 2171 (1986).

23. T. P. Skourlis and R. L. Mccullough, J. Appl. Polym. Sci., 62, 481 (1996).

24. J. O. Simpson and S. A. Bidstrup, J. Polym. Sci., Polym. Phys., 33, 55 (1995).

25. H. H. Winter, Polym. Eng. Sci., 27, 1698(1987).

26. H. H. Winter, "Encyclopedia of Polymer Science and Engineering", 2nd ed, Supplement Volume, 343, 1989.

27. P. A. Oyanguren and R. J. Williams, J. Appl. Polym. Sci., 47, 1361 (1993).

28. T. Takahama and P. H. Geil, J. Polym. Sci., 20, 453 (1982). 